\title{
Reliability of telepathology for frozen section service $^{1}$
}

\author{
Uwe Wellnitz $^{\mathrm{a}}$, Bernd Binder ${ }^{\mathrm{b}}$, Peter Fritz ${ }^{\mathrm{a}}$, \\ Godehard Friedel $^{\mathrm{c}}$ and Peter Schwarzmann ${ }^{\mathrm{b}}$ \\ ${ }^{a}$ Robert Bosch Hospital, Department of Pathology, \\ Stuttgart, Germany \\ ${ }^{\mathrm{b}}$ University of Stuttgart, Institute for Physical \\ Electronics, Stuttgart, Germany \\ ${ }^{\mathrm{c}}$ Department of Thoracic Surgery, Gerlingen, \\ Germany
}

One of the most promising applications of telepathology (pathology at a distance by electronic transmission of images in pathology) is frozen section diagnosis, especially because by means of this tool operations requiring an intraoperative histopathological diagnosis are feasible at hospitals without a pathologist on-site. For the introduction of this diagnostic tool into pathologist's daily practice the evidence of its diagnostic accuracy comparable to that of the conventional frozen section diagnosis is crucial.

For this purpose the literature on the diagnostic accuracy of telepathological frozen section diagnosis was reviewed.

In a metaanalysis these studies and reports, in which a total of more than 1290 cases had been examined, showed a slightly lower overall diagnostic accuracy (of the telepathological frozen section diagnosis) of about 0.91 than the conventional frozen section diagnosis with an average accuracy of about 0.98 found in an analysis of several studies (on frozen section diagnosis of different organs). This difference is at least predominantly caused by a higher rate of deferred and false negative frozen section diagnoses in the telepathological method, while the specificity of both methods, each more than 0.99 was not significantly different.

In conclusion, the introduction of a telepathological frozen section diagnosis for hospitals without an acceptable access to a pathologist is justifiable already at the current state of the technological development especially when considering the advantages (time saving, reduction in costs) compared to the alternative of surgical interventions without access to an intraoperative diagnosis.

Keywords: Telepathology, frozen section diagnosis, diagnostic accuracy, metaanalysis

\footnotetext{
${ }^{1}$ Supported by TeleKom AG Deutschland, the Robert Bosch Stiftung Stuttgart, and the Baden Württembergische Krebsverband.
}

\section{Introduction}

Modern telecommunication technology enables the electronic transmission of voluminous acoustic and visual information over long distances in a short time and at moderate costs. Its application in the field of medicine, termed telemedicine, offers new promising opportunities in the management of services in many medical specialties. Quality assurance and improvement especially by consultation of off-site experts are the most important aims of telemedicine. Furthermore, an increased cost effectiveness by improved utilization of medical resources in times of limited budgets in health care may be a benefit of telemedicine. Telemedical methods are tested in several medical specialties and extensive experiences have been gained in radiology, dermatology, surgery and pathology.

In the definition of SNOMED (Systemized Nomenclature of Medicine) telepathology is the performance of pathology at a distance using the available telecommunication links enabling the pathologists to render diagnoses and to consult each other remotely. In telepathology macroscopic and microscopic images are acquired by a videocamera and transmitted electronically to a receiving or display station, where they are re-visualized on a monitor and interpreted by a pathologist.

Images in telepathology are generated and transmitted in three basic modes: (i) online video conference mode with TV-frame rate, (ii) online video conference mode with reduced frame rate and (iii) collection and transmission of selected still images. In the still image mode a limited number of macroscopic or microscopic still images are selected, captured, digitized, stored and transmitted successively to the display station, where a pathologist views them immediately (online or interactive mode) or later (offline or store and forward mode) independently of the time of image transmission. By means of parallel audiocommunication and of telepointers still image telepathology can be performed in an interactive mode enabling an online discussion, e.g., about image details. As a rule still image 
Table 1

Commercially available telepathology systems equipped with remotely controlled microscopes

\begin{tabular}{|c|c|c|c|c|c|}
\hline Trade name & Manufacturer & Imaging mode & $\begin{array}{l}\text { Spatial resolution } \times \text { color } \\
\text { resolution }\end{array}$ & Host computer & Network link \\
\hline AutoCyte Link & TriPath Imaging, USA & $\begin{array}{l}\text { Software for AxioPath } \\
\text { (Zeiss) }\end{array}$ & & & \\
\hline AxioPath & $\begin{array}{l}\text { Carl Zeiss, FRG/ } \\
\text { TriPath Imaging, USA }\end{array}$ & $\begin{array}{l}\text { Reduced frame rate, } \\
\text { still image }\end{array}$ & $\begin{array}{l}\text { TV-frame } \times 24 \text { bit } \\
\text { ProGres camera }\end{array}$ & Pentium, WIN & ISDN \\
\hline CORABI & Apollo Inc., USA & $\begin{array}{l}\text { TV video conference, } \\
\text { still image }\end{array}$ & $\begin{array}{l}350 \times 288 \times 8 \text { bit video } \\
786 \times 486 \times 16 \text { bit still } \\
1520 \times 1144 \times 24 \text { bit still }\end{array}$ & Pentium, WIN & BRI, PRI-ISDN, T1 \\
\hline HISTKOM & $\begin{array}{l}\text { Deutsche Telekom AG, } \\
\text { FRG }\end{array}$ & $\begin{array}{l}\text { Reduced frame rate, } \\
\text { video conference, } \\
\text { online still image }\end{array}$ & $768 \times 576 \times 24$ bit & Pentium, WIN NT & 1-4 ISDN $\mathrm{S}_{0}$, ATM, LAN \\
\hline MIGRA & Olympus, Japan & $\begin{array}{l}\text { Video conference, } \\
\text { still image }\end{array}$ & TV-frame $\times 24$ bit & PC, WIN & H.320, ISDN \\
\hline PathSight & $\begin{array}{l}\text { Fairfield Imaging Ltd., } \\
\text { UK }\end{array}$ & $\begin{array}{l}\text { Video telephone, } \\
\text { still image }\end{array}$ & $\begin{array}{l}24 \text { bit color for still } \\
\text { image }\end{array}$ & WIN & LAN, VSAT, ATM, ISDN \\
\hline TPS1 & $\begin{array}{l}\text { Leica Microsystems, } \\
\text { FRG }\end{array}$ & $\begin{array}{l}\text { Reduced frame rate, } \\
\text { still image }\end{array}$ & TV-frame $\times 24$ bit & PC, WIN & ISDN \\
\hline ZEM Dynamic & Nikon, Japan & $\begin{array}{l}\text { Reduced frame rate, } \\
\text { still image }\end{array}$ & & PC, WIN & \\
\hline
\end{tabular}

telepathology systems do not include a remote control of the microscope. The lack of a remotely controllable robotic microscope implies the risk of misinterpretation caused by the lack of transmission of diagnostically relevant images. The main applications of still image telepathology are teleconsultation, telemeasurement and teleeducation $[18,20]$.

In the US literature the term dynamic telepathology is used for online video conference systems for pathological live images with TV frame rates [20,21].

Differing from the American convention, in Europe the term dynamic is used for all remotely controlled telemicroscopy systems and the term static for all still image transmission systems. In Europe additionally the definitions active (for remotely controlled microscopy) and passive (for not remotely controlled microscopy) are common.

To avoid any confusion, in our article we will use the term remotely controlled microscopy (as, e.g., HISTKOM) for all systems with robotic microscopes (telemicroscopes) and a live transmission of images, be it with TV-frame rates or reduced frame rates. Systems without remotely controlled microscopes we will call still image telepathology systems be it in an interactive or a store and forward mode.

The image transmission of remotely controlled telepathology systems needs high-capacity telecommunication links with transfer rates of at least $384 \mathrm{kbit} / \mathrm{s}$
(3 ISDN $\mathrm{S}_{0}$-telephone channels for video conference systems) up to $144 \mathrm{Mbits} / \mathrm{s}$ (not compressed online video connections in studio quality). Telepathology with robotic microscopy systems is used mainly for a primary diagnostic service, especially a frozen section service for a hospital or health care provider without a pathologist on-site.

Remotely controlled and not remotely controlled telepathology do not exclude each other - many systems with robotic microscopes also may be operated as still image systems - some investigators have reported on such hybrid systems $[3,5,7,26]$. Some studies indicate, that the diagnostic accuracy achievable with a remotely controlled telepathology system is higher than that achievable with a not remotely controlled system [5,15,34].

In Table 1 the manufacturers and basic technical features of commercially available telepathology systems with remotely operated microscopes are listed. The listing of still image systems is difficult, as studies have been carried out with systems very varyingly specialized in telepathology. We find studies of investigators, who are familiar with computer science and who apply standard image grabbing and image transmission facilities of network software as well as systems with software specialized in telepathology applications in routine daily workflow.

The methods of telepathology can be applied to most pathologists' activities like gross and micro- 
Table 2

\begin{tabular}{|c|c|c|c|c|c|}
\hline $\begin{array}{l}\text { Authors } \\
\text { (reference) }\end{array}$ & Organ & $\begin{array}{l}\text { Number } \\
\text { of cases }\end{array}$ & Sensitivity & Specifity & Accuracy \\
\hline [2] & $\begin{array}{l}\text { Nonpalpable breast } \\
\text { Lesions }\end{array}$ & 672 & 0.917 & 0.992 & 0.958 \\
\hline [9] & Breast & 4436 & 0.946 & 1 & 0.983 \\
\hline$[17]$ & Breast & 432 & 0.975 & 1 & 0.965 \\
\hline [24] & $\begin{array}{l}\text { Sentinel lymph nodes } \\
\text { in breast cancer }\end{array}$ & 101 & 0.520 & 1 & 0.881 \\
\hline$[16]$ & Thyroid gland & 240 & 0.67 & 0.99 & 0.89 \\
\hline [23] & Thyroid gland & 812 & 0.913 & 1 & 0.974 \\
\hline$[22]$ & Ovar & 173 & & & 0.971 \\
\hline [42] & Ovar & 316 & 0.87 & & 0.952 \\
\hline [38] & Gynecologic surgery & 792 & 0.909 & 0.995 & 0.975 \\
\hline [8] & Mixed & 24,880 & & & 0.978 \\
\hline$[13]$ & Mixed & 90,538 & & & 0.986 \\
\hline [33] & Mixed & 2,250 & 0.889 & 0.979 & 0.949 \\
\hline Mean & & & 0.900 & 0.994 & 0.983 \\
\hline
\end{tabular}

scopic examination of tissue samples, expert consultation, continuing education and quantitative image analysis. Among these, the provision of a frozen section service for hospitals or medical institutions without a pathologist on-site is one of the most promising applications of telepathology, because several attractive opportunities come up:

- frozen section service also for small and medium hospitals,

- reduction of operation time by avoiding the transport of the tissue sample,

- surgical treatment of more patients near to their residence,

- reduction in costs (e.g., by reduction of subsequent surgical interventions),

- provision of developing countries with affordable services in pathology.

However, a frozen section service is a very challenging application of telepathology and pathology in general because of the limited technical quality of the specimen and the time pressure while rendering a diagnosis resulting in high demands on the technical equipment. To be able to justify the introduction of telepathological frozen section diagnosis into the daily practice, its technical feasibility and the concordance or at most insignificant deviation of its diagnostic accuracy compared with that of the conventional frozen section diagnosis have to be shown in studies and fieldtests. To the opinion of the authors, in medical facilities without access to a frozen section service at accep- table conditions as, for instance, in smaller and remote hospitals or in developing countries a telepathological frozen section service would be acceptable even in the case of its slightly lower sensitivity, in developing countries additionally a lower specificity may be acceptable.

The following review deals with studies and reports on the feasibility and diagnostic accuracy of primary telepathological frozen section diagnosis as a service for hospitals without a pathologist on-site. The design and the essential results of the cited studies are summarized in Table 3. As benchmark for the conventional frozen section diagnosis, levels of diagnostic accuracy between 0.88 and 0.99 have been reported (Table 2).

\section{Review}

The most important decision to be made in frozen section analysis is the determination of the dignity of the submitted lesion. Accordingly, in all cited studies the classification of a frozen section diagnosis as correct or incorrect is made according to the correct or incorrect assessment of the dignity. Concerning the calculation of the statistic parameters of diagnostic accuracy, the deferred diagnoses were classified as incorrect. In all studies reference was the diagnosis established on paraffin embedded tissue.

In Europe, a routine telepathological frozen section service in daily practice is established by the Departments of Pathology of the Universities of Tromsö, Nor- 
Table 3

Diagnostic accuracy of telepathological frozen section diagnosis

\begin{tabular}{|c|c|c|c|c|c|c|c|c|}
\hline $\begin{array}{c}\text { Authors } \\
\text { (reference) }\end{array}$ & & Organ & $\begin{array}{l}\text { Number } \\
\text { of cases }\end{array}$ & $\begin{array}{l}\text { Imaging } \\
\text { mode }\end{array}$ & $\begin{array}{l}\text { Remote } \\
\text { control }\end{array}$ & Telenetwork & $\begin{array}{c}\text { Rate of } \\
\text { deferred } \\
\text { diagnoses }\end{array}$ & Sensitivity \\
\hline$[26]$ & Prospective & Mixed & 100 & Live & Yes & $\begin{array}{l}\text { Video conference network } \\
(2 \mathrm{Mbit} / \mathrm{s}), \mathrm{ISDN}(384 \mathrm{kbit} / \mathrm{s})\end{array}$ & 0.070 & 0.77 \\
\hline [27] & Prospective & Mixed & 53 & Still & Yes & ISDN (64/128 kbit/s) & 0.043 & 0.857 \\
\hline$[36]$ & Prospective & Mixed & 94 & Still & Yes & ISDN (64?/128 kbit/s) & 0.043 & 0.92 \\
\hline$[35]$ & prospective & Mixed ( $92.5 \%$ breast) & 270 & & No & & & \\
\hline [34] & Prospective & Mixed & 14 & Live & Yes & Glass fiber & 0 & \\
\hline [34] & Prospective & $\begin{array}{l}\text { Mixed } \\
\text { (81\% lung/media stinum) }\end{array}$ & 16 & Still & No? & ISDN (64 kbit/s) & 0 & \\
\hline$[12]$ & Prospective & Mixed & 135 & Still & No & $\begin{array}{l}\text { Standard telephone line } \\
(9.6 \mathrm{kbit} / \mathrm{s})\end{array}$ & 0.052 & 0.929 \\
\hline$[1]$ & Prospective & Mixed & 117 & Still & No & ISDN (64 kbit/s) & 0 & \\
\hline$[37]$ & Prospective & & & Still & Yes & ISDN (64 kbit/s?) & & \\
\hline$[3]$ & Prospective & & 60 & Hybrid & Yes & $4 \times$ ISDN & & \\
\hline [41] & Retrospective & Thoracic surgery & 109 & Live & Yes & ISDN (64 kbit/s) & 0.101 & 0.67 \\
\hline [31] & Retrospective & Breast & 139 & Live & Yes & ISDN (512 kbit/s) & 0.029 & \\
\hline & & & 139 & & & & 0.029 & \\
\hline$[31]$ & Prospective & Mixed & 47 & Live & Yes & ISDN (512 kbit/s) & 0.192 & \\
\hline Mean & & & & & & & 0.050 & 0.830 \\
\hline
\end{tabular}

way and Basel, Switzerland and by the private Institute of Pathology at the Community Hospital in Aurich, Germany. Further test periods and systems in introduction into the daily workflow have been reported in Germany by the Hospital in Munich Harlaching, the Charité in Berlin, the University Hospital in Gießen and the Hospital Friedrichstadt in Dresden. Since 1990 the Department of Pathology, University of Tromsö, Norway provides a telepathological frozen section service for initially one, later two local hospitals up to $420 \mathrm{~km}$ away using a telepathology system equipped with microscopes remotely controllable in all functions (scanning stage, focus, selection of objectives and illumination), a 1-chip camera and a videocodec for visual data compression $[6,7,26]$. As communication link a twoway audio and video telenetwork with a transmission rate of $2 \mathrm{Mbit} / \mathrm{s}$ until 1992 and afterwards with a standard transfer rate of $384 \mathrm{kbit} / \mathrm{s}$ was or is used, this reduction of the transmission capacity did not show any negative effect on the practice of telediagnosing. Until July 1994 the frozen sections of 100 cases from different organs (52\% specimens of the breast) were examined telepathologically resulting in a sensitivity of 0.77 , a specificity of 0.92 and an accuracy of 0.89 . The average time needed for the telemicroscopical examination of each case was $12 \mathrm{~min}$ (range 3-45 min) with a decreasing trend in the later periods of the diagnostic service. The average total consultation time per case including the time for macroscopic gross examination, frozen section preparation and microscopic examination was $37 \mathrm{~min}$ (range 20-65 $\mathrm{min}$ ).

Since 1992 the Department of Pathology, University of Basel, Switzerland serves two regional hospitals up to $250 \mathrm{~km}$ away with a telepathological frozen section service using remotely controllable microscopes and the ISDN with a transfer rate of $64 \mathrm{kbit} / \mathrm{s}$ until 1993 and afterwards of $128 \mathrm{kbit} / \mathrm{s}$ [27-29]. The microscopes are equipped with a 1-chip CCD camera and an autofocus function, they are driven not only by remote control, but also directly by the technician at the surgeon's site who is guided telephonically by the consulted pathologist to select microscopic fields of view for transmission. The scrutiny of 53 cases until 1994 revealed a sensitivity of 0.857 and a specificity of 1.0. On average seven to eight (range 2-14) images per case were transmitted, the time needed for the complete frozen section consultation ranged from 20 to $40 \mathrm{~min}$. In an extension of this series $(n=94)$ a sensitivity of 0.92 , a specificity of 1.0 and an accuracy of 0.89 were found [36].

The private Institute of Pathology, Community Hospital in Aurich, Germany has established a telepathological frozen section service for the Community Hospital Ammerland/Westerstede [35]. For this purpose an economical telepathology system based on an 
ISDN-connection of two B-channels (128 kbit/s) and equipped with a not remotely controlled microscope, a 1-chip CCD camera, an additional CCD camera for acquisition of macroscopic images, a frame grabber at the peripheral site and a display monitor at the pathologist's site was installed. The selection of the area of the removed tissue sample for frozen sectioning is made by the surgeon, who trims the sample to a size of $10 \times$ $6 \times 4 \mathrm{~mm}$. At the beginning of the microscopic examination an overview of the frozen section slide is transmitted in low magnification and afterwards the pathologist guides a technician telephonically by orientation in an underlayed square scale to select microscopic fields for transmission in higher magnification. In the examination of 270 frozen sections $(92.5 \%$ breast lesions) within one year an overall diagnostic accuracy of 0.885 and an accuracy with respect to the breast lesions of 0.905 were achieved. The telepathological examination of each case took 15-20 min.

Prospective studies on the diagnostic validity of telepathological frozen section diagnosis were carried out by Kayser et al. [19-21], Shimosato et al. [34], Fujita et al. [12], Adachi et al. [1], and Tsuchihashi et al. [37] in Japan, Goncalves and Cunha in Portugal [14], Nordrum et al. [25,26] in Norway and Cataldi et al. [3] and Della Mea et al. [4] in Italy.

Shimosato et al. compared a high definition television (HDTV) video image telepathology system based on a glass fiber connection and equipped with a remotely controlled microscope with an ISDNconnected HDTV still image system with a transmission rate of $64 \mathrm{kbit} / \mathrm{s}$ [34]. The telepathological examination of the frozen sections of 14 cases with the video HDTV system resulted in an accuracy of 0.857 and a rate of permissible diagnoses (which means diagnoses not affecting the choice of therapy) of 0.929 . The analysis of 16 frozen sections with the ISDN HDTV still image system revealed a lower accuracy of 0.688 and a rate of diagnoses in a permissible range of 1.0. Shimosato and his coworkers assessed the video HDTV system to be suitable, the ISDN-based still image system to be not suitable for telepathological frozen section diagnosis.

Fujita et al. evaluated the validity of frozen section diagnosis achievable with a still image based telepathology system (Pathtran 1000) equipped with a not remotely controlled microscope and a CCD videocamera $(768 \times 494$ pixels) [12]. The sending and receiving sites were $120 \mathrm{~km}$ apart and connected by a standard analogue telephone line with a maximum transmission rate of $9.6 \mathrm{kbit} / \mathrm{s}$. The selection of the part of the excised lesion to be frozen sectioned and of the microscopic fields to be transmitted was performed by a cytotechnologist trained in histopathology screening after he had been instructed how to select the most likely diagnostic microscopic fields. The pathologist was informed via fax about the macroscopic findings, additionally, macroscopic images were transmitted if necessary. The telepathological frozen section diagnoses of 135 tissue samples of different organs showed a sensitivity of 0.929 , a specificity of 0.957 and an accuracy of 0.948 . $3.8 \pm 1.7$ (range 1-10) images per case were transmitted, the average time elapsed from receiving the fax until establishing a diagnosis was approximately $20 \mathrm{~min}$.

Further experiences with telepathological frozen section diagnosis based on still images have been reported by Adachi et al. [1]. They used a telepathology system with a not remotely controlled microscope, a RGB 3-chip CCD camera $(768 \times 480$ pixels), a video monitor and the ISDN-net with a transfer rate of $64 \mathrm{kbit} / \mathrm{s}$. To reduce the risk of misinterpretation caused by selection of inappropriate microscopic fields, specimens measuring more than $1 \mathrm{~cm}$ in diameter as well as surgical margins were excluded from the telepathological examination. The examination of 117 specimens of different organs reached a diagnostic accuracy of 0.932 . On average 6.2 (range 230) still images were transmitted per case, the average time needed for the examination of each specimen was 13 min (range 2-42 min).

Tsuchihashi et al. investigated the diagnostic efficiency and cost-effectiveness of still image based telepathology by use of the Olmicos system (Olympus, Japan), which is equipped with a fully remotely controllable robotic microscope and a 3-chip CCD camera (400,000 pixels) [37]. (In the classification of this paper this type belongs to the class of remotely operated systems.) The local hospital and the pathologist's location are about $100 \mathrm{~km}$ apart and were connected by two ISDN B-channels each with a transmission capacity of $64 \mathrm{kbit} / \mathrm{s}$. One channel was used for image transmission and the other for audio communication. In a test period of five years, during which predominantly frozen sections had been examined, a diagnostic accuracy of more than 0.98 was achieved. The time required for a telepathological diagnosis varied considerably between less than 15 and more than $30 \mathrm{~min}$ in some cases. No data concerning the number of examined cases and frozen sections, respectively, the topographic origin, the gross examination of the removed tissue as well as the sensitivity and specificity are reported. 
Cataldi et al. and Della Mea et al. evaluated the diagnostic efficacy of the MIGRA system (Olympus, Germany), a hybrid telepathology system combining a video conference and a still image subsystem [3,4]; it includes a remotely controlled microscope. The Department of Pathology of the University of Udine and the Laboratory of Pathology of the Hospital of Tolmezzo, $60 \mathrm{~km}$ apart, both Italy were connected by four ISDN lines for bidirectional image transfer, three lines were assigned to the video conference, one to the still image subsystem. The video conference subsystem is based on the H.320 protocol. The examination of 60 frozen sections resulted in an accuracy of 1.0. The average time needed was $4.1 \mathrm{~min}$ (range 1 to $18 \mathrm{~min}$ ); per case on average 1.5 still images were transferred additionally to the video conference scenes. As the authors of the paper are involved in the development of the HISTKOM system, the data of this system are reported in more detail.

The Deutsche Telekom AG, Bonn, and the Institute for Physical Electronics, University of Stuttgart, both Germany have developed the robotic telemicroscopy system HISTKOM for telepathology considering especially the requirements of frozen section analysis. This system is equipped with a remotely driven robotic microscope and a 3-chip color-Sony TVcamera. HISTKOM can be operated in a video conference mode, a reduced frame rate mode and a still image mode. The JPEG-standard is applied for coding and compression of image data; its parameters are permanently adapted to the image content and the user behavior; ISDN lines are the preferred telecommunication link but all networks with a TCP/IP interface may be applied (ATM, VSAT, Internet, etc.). HISTKOM offers the facility to bundle up to 4 ISDN $\mathrm{S}_{0}$-channels (512 kbit/s) to provide a comfortable working environment. The diagnostic accuracy achievable with this system was evaluated in several field tests and in daily practice by the examination of paraffin embedded tissue, of frozen sections and of cytological material in a partly prospective, partly retrospective mode.

In the first field test a retrospective study with an experimental version of HISTKOM, performed by the Department of Pathology, Robert-Bosch-Hospital, Stuttgart, Germany, was carried out with frozen sections of archival, exclusively thoracosurgical cases applying only one ISDN B-channel (64 kbit/s) [31,41]. The clinical information about the cases was the same as at the time of primary diagnosis. The telepathological diagnoses of 109 frozen sections showed a sensitivity of 0.67 , a specificity of 0.90 and an accuracy of 0.81 , significantly lower values of sensitivity and accuracy compared with the corresponding parameters of the conventional frozen section diagnoses of the same cases. The rate of deferred telemicroscopical diagnoses (0.101) was significantly higher than that of the frozen section diagnoses established by direct light microscopy (0.018), whereas the telepathological and conventional procedure yielded an identical false positive rate of 0.009 . The time consumption for rendering a telepathological diagnosis was fairly high, on average it amounted to $47.1 \mathrm{~min}$ per case, also due to cases in which the whole specimen or resection borders had to be investigated. The conclusion of the study was, that only one ISDN channel is insufficient for a comfortable workflow in daily routine frozen section telepathology.

After the net connection had been upgraded to 4 ISDN $\mathrm{S}_{0}$-channels in parallel (512 kbits/s), a subsequent retrospective field test with HISTKOM was performed by two pathologists at the Institute of Pathology, University of Tübingen, Germany [30,31]. The reexamination of 139 frozen sections exclusively from breast tissue samples resulted in a concordance rate of 0.971 and 0.957 and a false negative rate of 0 and 0.014 for the two pathologists. The telemicroscopical diagnoses of both pathologists showed an identical false positive rate of 0 and rate of deferrals of 0.029 . The average time consumption per case was 3.7 and $2.4 \mathrm{~min}$.

A further field test with the HISTKOM system was carried out in a prospective mode by the Department of Pathology at the Hospital in Bernburg and the Department of Surgery of the Hospital in Köthen, both Germany [31]. In this study HISTKOM was also operated with 4 ISDN $\mathrm{S}_{0}$-channels. To meet the legal regulations, a pathologist on-site at the surgery department diagnosed the frozen sections in parallel by direct light microscopy. The concluding frozen section diagnosis was established in consensus of the remote and the on-site pathologist. The examination of 47 tissue samples of different organs achieved a concordance rate of 0.787 , a false negative rate of 0.021 , a false positive rate of 0 and a rate of deferred diagnoses of 0.192 . Data concerning the time consumption are not given in the report on this study.

The Department of Pathology at the Hospital in Munich Harlaching evaluated the HISTKOM telepathology equipment in the workflow of thyroid surgery [32]. In the test period the frozen sections of 98 consecutive thyroid tissue samples were investigated in a safe way: benign lesions were diagnosed immediately by telepathology, in the case of a not clearly benign le- 
sion the telepathological frozen section diagnosis was deferred and the slide and the tissue sample were transported by taxi to the department of pathology for conventional diagnosis. 89 benign lesions were correctly diagnosed by telepathology (false negative rate 0 ), of the 9 lesions assessed as doubtful by telepathology 5 cases were diagnosed as adenoma and 4 cases as carcinoma by conventional microscopy.

\section{Discussion}

Misdiagnoses in the telepathological examination of frozen sections can be attributed to 4 kinds of error:

(1) selection of an inappropriate tissue sample for frozen sectioning (error in gross examination),

(2) selection and transmission of inappropriate microscopic fields especially in not remotely controlled telepathology,

(3) misinterpretation due to insufficient image quality, and

(4) misinterpretation in spite of adequate images of sufficient quality.

While the last kind of error is not related to the procedure of telepathology the first three sources of error may be due to or aggravated by telepathology, and thus they can cause a reduction of the diagnostic accuracy of the telepathological frozen section diagnosis compared with that of the conventional one. Accordingly in the cited studies, on average the telepathological frozen section diagnosis achieves a slightly lower level of diagnostic accuracy of about 0.91 than the frozen section diagnosis by direct light microscopy with an accuracy of about 0.98 as indicated by the results of the studies listed in Table 2. It is important to realize, that this difference at least predominantly is due to a higher rate of deferred and false negative diagnoses. A false positive diagnosis was given only in seven cases of the total of at least 1293 cases examined in the cited studies resulting in a specificity comparable to that of the conventional frozen section diagnosis of more than 0.99 , when deferred diagnoses are excluded from evaluation.

The gross examination of the tissue sample by a non-pathologist in a primary telepathological diagnostic service assumedly increases the risk of selection of inappropriate tissue for the microscopic examination. A study to verify and estimate the significance of this source of error is difficult to design and also the cited retrospective studies do not allow conclusions on the significance of this source of error, because they do not show a trend to higher levels of diagnostic accuracy compared with the prospective studies. In some telepathology systems the problems of gross examination are considered by the transmission of macroscopic images of the tissue sample and a subsequent visual and acoustic guidance of tissue sampling by the telepathologist $[7,12,27,31,36]$. The risk of sampling error should be reduced additionally by education and continuous training of a member of the surgeon's team in gross examination of tissue samples. But the lack of a direct and palpatoric examination by a pathologist remains a yet unsolved problem of a primary telepathological diagnostic service.

Unlike the consequences of inappropriate tissue sampling the effects on diagnostic accuracy of telepathological frozen section diagnosis caused by selection of inappropriate microscopic fields (in systems without robotic microscopes) and insufficient image quality can be estimated by the difference of diagnostic accuracy of the conventional and telepathological diagnoses rendered at the same series of frozen sections. Such a comparison of the telepathological and conventional frozen section diagnoses was performed only in 2 retrospective studies $[39,41]$, in one of these studies [41] carried out with archival cases of thoracic surgery this comparison revealed a significantly lower sensitivity and accuracy of the telepathological frozen section diagnosis which to a high degree might be caused by the low transmission rate applied in this study (64 kbit/s). Astonishingly and in contrast to the results of studies on the validity of primary telepathological diagnosis of paraffin embedded tissue, the studies on the telepathological frozen section diagnosis, in which a still image based telepathology system without remotely controlled microscopes was used, do not show a trend to a lower diagnostic accuracy compared with those in which a video conference system was used. Thus a negative effect on the diagnostic accuracy (of frozen section diagnosis) by inappropriate microscopic field selection in not remotely controlled telepathology is not verifiable by the results of the cited studies, whereas Shimosato et al., Weinstein et al. and Weinstein et al. recommend remotely controlled microscopy equipment for primary telepathological diagnosis to enable an active microscopic field selection by the remote pathologist him- or herself $[34,39,40]$.

In most studies the ISDN was used for telecommunication link, indicating, that this telenetwork provides the best compromise concerning online capabilities, availability and cost effectiveness of the currently accessible communication links. The Internet is 
best suited for all offline telepathology services, where small delays in reactions can be accepted.

The results reported concerning the diagnostic quality of telepathology in the frozen section scenario are diffuse. Most studies do not report the degree of difficulty of a case nor the investigation done: was it just an assessment of the dignity of a clear case, was it an investigation of a complete resection border or was it a search in the slide for rare events? These data influence the time needed for an investigation and the requirements to the working comfort of a telepathology system to a high degree. Also most studies do not report whether the cases have been selected for the study or whether unselected cases have been examined. It will be the task of the first installations of telepathology equipment to report on experiences with telepathology in a routine workflow operation.

In conclusion, the cited studies demonstrate a slight, but (to the opinion of the authors) acceptable decrease in diagnostic accuracy of a telepathological cryostat section service. This is compensated by advantages such as time saving in frozen section scenarios without a pathologist on-site and an overall access to a frozen section diagnosis also for remote, small and medium hospitals. To the opinion of the authors the data of the studies suggest, that an introduction of a telepathological frozen section service for remote hospitals without an acceptable access to a pathologist on-site can be justified already at the current state of the technological development.

\section{Outlook}

Technical progress in image analysis, computer technology and telematics is rapidly ongoing. Therefore, one may foresee some new qualities of frozen section diagnosis which are realizable only by modern telecommunication technology:

- the assessment of the quality of the images used for the frozen section diagnosis by methods of image analysis $[10,11]$, if necessary a frozen section diagnosis is to refuse for bad quality;

- online teleconsultation of reference pathologists with special knowledge, e.g., in the field of soft tissue tumors during the frozen section diagnosis;

- quantitation and assessment of mathematical features of the microscopic image. A squamous cell carcinoma currently diagnosed may be compared with collected data of squamous cell carcinomas diagnosed earlier and a probability may be calculated that the given descriptors of the currently diagnosed case are compatible with those of the squamous cell carcinomas registered in the data bank;

- in the fields of microinvasive surgery, computer assisted surgery and telesurgery great efforts are made to develop sensors and presentation equipment for tactile sensations (telefeeling). The near future will demonstrate, whether these developments will be suitable also for telepathology, to provide the remote pathologist with the last tool he is missing still - the tactile impression - to have all opportunities he has in the conventional frozen section scenario.

Therefore, modern techniques of image analysis, telecommunication, and telematics may change the present mode of frozen section technology and offer new perspectives to a conventional method.

\section{References}

[1] H. Adachi, J. Inoue, T. Nozu, H. Aoki and H. Ito, Frozensection services by telepathology: experience of 100 cases in the San-in District, Japan, Pathol. Int. 46(6) (1996), 436-441.

[2] S. Bianchi, D. Palli, S. Ciatto, M. Galli, D. Giorgi, V. Vezzosi, M. Rosselli del Turco, L. Cataliotti, G. Cardona and G. Zampi, Accuracy and reliability of frozen section diagnosis in a series of 672 nonpalpable breast lesions, Am. J. Clin. Pathol. 103 (1995), 199-205.

[3] P. Cataldi, B. Pertoldi, V. Della Mea and A. Beltrami, Validation of realtime telemicroscopy. A preliminary report on 184 cases, Adv. Clin. Pathol. 2 (1998), 139-140.

[4] V. Della Mea, P. Cataldi, B. Pertoldi and C.A. Beltrami, Dynamic robotic telepathology: a preliminary evaluation on frozen sections, histology and cytology, J. Telemed. Telecare 5(Suppl. 1) (1999), 55-56.

[5] B.E. Dunn, U.A. Almagro, H. Choi, N.K. Sheth, J.S. Arnold, D.L. Recla, E.A. Krupinski, A.R. Graham and R.S. Weinstein, Dynamic-robotic telepathology: Department of Veterans Affairs feasibility study, Hum. Pathol. 28 (1997), 8-12.

[6] T.J. Eide and I. Nordrum, Current status of telepathology, $A P$ MIS 102 (1994), 881-890.

[7] T.J. Eide and I. Nordrum, Frozen section via the telenetwork in Northern Norway, Zentralbl. Pathol. 138 (1992), 409-412.

[8] J.A. Ferreiro, J.L. Myers and D.G. Bostwick, Accuracy of frozen section diagnosis in surgical pathology: review of a 1year experience with 24,880 cases at Mayo Clinic Rochester, Mayo Clin. Proc. 70 (1995), 1137-1141.

[9] L. Fessia, B. Ghiringhello, R. Arisio, G. Botta and V. Aimone, Accuracy of frozen section diagnosis in breast cancer detection. A review of 4436 biopsies and comparison with cytodiagnosis, Pathol. Res. Pract. 179 (1984), 61-66. 
[10] P. Fritz, H.V. Tuczek, B. Öffinger, P. Schwarzmann, S. Schieszl, X. Wu, B. Kleine, J. Blödorn and H. Multhaupt, Immunohistochemical quantification of steroid receptors and other prognosis factors in human breast cancer patients, Progr. Histochem. Cytochem. 26 (1992), 146-158.

[11] P. Fritz, X. Wu, H. Tuczek, H. Multhaupt and P. Schwarzmann, Quantitation in immunohistochemistry. A research method or a diagnostic tool in surgical pathology?, Pathologica 87 (1995), 300-309.

[12] M. Fujita, Y. Suzuki, M. Takahashi, K. Tsukamoto and K. Nagashima, The validity of intraoperative frozen section diagnosis based on video-microscopy (telepathology), Gen. Diagn. Pathol. 141 (1995), 105-110.

[13] G.N. Gephardt and R.J. Zarbo, Interinstitutional comparison of frozen section consultations. A college of American Pathologists Q-Probes study of 90,538 cases in 461 institutions, Arch. Pathol. Lab. Med. 120 (1996), 804-809.

[14] L. Goncalves and C. Cunha, One year experience with telepathology for frozen sections, Elec. J. Pathol. Histol. 1(4) (1995), No. 954-09.

[15] B. E. Halliday, A.K. Bhattacharyya, A.R. Graham, J.R. Davis, S.A. Leavitt, R.B. Nagle, W.J. McLaughlin, R.A. Rivas, R. Martinez, E.A. Krupinski and R.S. Weinstein, Diagnostic accuracy of an international static-imaging telepathology consultation service, Hum. Pathol. 28 (1997), 17-21.

[16] J.F. Hamming, M.R. Vriens, B.M. Goslings, I. Songun, G.J. Fleuren and C.J. van de Velde, Role of fine-needle aspiration biopsy and frozen section examination in determining the extent of thyroidectomy, World J. Surg. 22 (1998), 575-579.

[17] E. Hanzal, G. Gitsch, E. Joura, C. Dadak and G. Breitenecker, Die Wertigkeit der intraoperativen Schnellschnittuntersuchung in der Diagnostik des Mammakarzinoms, Geburtsh. Frauenheilk 52 (1992), 161-164.

[18] K. Kayser and C. Kayser, Telepathology - aspects of social influence and quality control, Elec. J. Pathol. Histol. 3(3) (1996), No. 963-04.

[19] K. Kayser, G. Kayser and S. Zink, New technical aspects in telepathology, Elec. J. Pathol. Histol. 6(3) (2000), No. 003-04.

[20] K. Kayser, J. Szymas and R. Weinstein, Telepathology Telecommunication, Electronic Education and Publication in Pathology, Springer, Heidelberg, New York, 1999.

[21] K. Kayser and G. Kayser, Basic Aspects of and Recent development of telepathology in Europe with specific emphasis on quality assurance, J. Anal. Quant. Cytol. Histol. 21 (1999), 319-328.

[22] F.K. Lim, C.L. Yeoh, S.M. Chong and S. Arulkumaran, Pre and intraoperative diagnosis of ovarian tumours: how accurate are we?, Aust. N. Z. J. Obstet. Gynaecol. 37 (1997), 223-227.

[23] P.P. Morosini, V. Mancini, S. Filipponi, A. Taccaliti, M. Ferretti, P. Gusella, A. Vecchi, A. Fianchini and G. Fabris, Comparison between the diagnostic accuracy in diagnosis of thyroid nodules with fine needle biopsy and intraoperative histological evaluation of frozen tissue, Minerva Endocrinol. 22 (1997), $1-5$.

[24] K. Motomura, H. Inaji, Y. Komoike, T. Kasugai, S. Nagumo, S. Noguchi and H. Koyama, Intraoperative sentinel lymph node examination by imprint cytology and frozen sectioning during breast surgery, Br. J. Surg. 87 (2000), 597-601.
[25] I. Nordrum, B. Engum, E. Rinde, A. Finseth, H. Ericsson, M. Kearney, H. Stalsberg and T.J. Eide, Remote frozen section service: a telepathology project in Northern Norway, Hum. Pathol. 22 (1991), 514-518.

[26] I. Nordrum and T.J. Eide, Remote frozen section service in Norway, Arch. Anat. Cytol. Pathol. 43 (1995), 253-256.

[27] M. Oberholzer, H.R. Fischer, H. Christen, S. Gerber, M. Brühlmann, M.J. Mihatsch, T. Gahm, M. Famos, C. Winkler, P. Fehr, H.J. Hosch and L. Bächtold, Telepathology: frozen section diagnosis at a distance, Virchows Arch. 426 (1995), 3-9.

[28] M. Oberholzer, H.R. Fischer, H. Christen, S. Gerber, M. Brühlmann, M. Mihatsch, M. Famos, C. Winkler, P. Fehr, H.J. Hosch, L. Bächthold and K. Kayser, Telepathology with an integrated services digital network - a new tool for image transfer in surgical pathology: a preliminary report, Hum. Pathol. 24 (1993), 1078-1085.

[29] M. Oberholzer, H.R. Fischer, H. Christen, S. Gerber, M. Brühlmann, M. Famos, C. Winkler, P. Fehr and L. Bächtold, Telepathology with an integrated services digital network. A new tool in pathology, in: The Computerized Cytology and Histology Laboratory. Compendium on the Computerized Cytology and Histology Laboratory, G.L. Wied, P. Bartels, D. Rosenthal and U. Schenck, eds, Tutorials of Cytology, Chicago, pp. 295-305.

[30] J. Schmid, P. Schwarzmann, B. Binder, J. Burkhart and R. Klose, Field test to evaluate telepathology with remotely driven microscopy - project HISTKOM, Cell Vision 3 (1996), 479-481.

[31] P. Schwarzmann, B. Binder, M. Käser and R. Klose, European field tests with HISTKOM telepathology equipment, in: The Impact of Telemedicine on Health Care Management, M. Nerlich and R. Kretschmer, eds, IOS press, 1999, pp. 192-207.

[32] P. Schwarzmann, B. Bültmann, W. Nathrath, P. Fritz, J. Knolle and U. Schenck, Feldtests in der Pathologie mit HISTKOM - Ergebnisse und Erfahrungen, in: Telemedizinführer Deutschland 2001, A. Jäckel, ed., Minerva, Nov. 2000, pp. 227-232.

[33] L.F. Scucchi, D. Di Stefano, L. Cosentino and A. Vecchione, Value of cytology as an adjunctive intraoperative diagnostic method. An audit of 2,250 consecutive cases, Acta Cytol. 41 (1997), 1489-1496.

[34] Y. Shimosato, Y. Yagi, K. Yamagishi, K. Mukai, S. Hirohashi, T. Matsumoto and T. Kodama, Experience and present status of telepathology in the National Cancer Center Hospital, Tokyo, Zentralbl. Pathol. 138 (1992), 413-417.

[35] G. Stauch, K.W. Schweppe and M. Putz, One year experience with telepathology for frozen sections, Elec. J. Pathol. Histol. 1(4) (1995), No. 954-08.

[36] B. Steffen, D. Gianom, C. Winkler, H.J. Hosch, M. Oberholzer and M. Famos, Schnellschnittuntersuchung mittels Telepathologie, Swiss Surg. 3 (1997), 25-29.

[37] Y. Tsuchihashi, T. Mazaki, S. Murata, K. Nakasato, M. Morishima, H. Nagata, I. Tofukiji and K. Naitoh, Telepathology and cytology in Kyoto, Japan, to support regional medicine, with special references to their need, accuracy and cost, $A d v$. Clin. Path. 2 (1998), 131-132.

[38] K.G. Wang, T.C. Chen, T.Y. Wang, Y.C. Yang and T.H. Su, Accuracy of frozen section diagnosis in gynecology, Gynecol. Oncol. 70 (1998), 105-110. 
[39] L.J. Weinstein, J.I. Epstein, D. Edlow and W.H. Westra, Static image analysis of skin specimens: The application of telepathology to frozen section evaluation, Hum. Pathol. 28 (1997), 30-35.

[40] R.S. Weinstein, Static image telepathology in perspective, Hum. Pathol. 27 (1996), 99-101.

[41] U. Wellnitz, P. Fritz, V. Voudouri, A. Linder, H. Toomes, J. Schmid, B. Binder and P. Schwarzmann, The validity of telepathological frozen section diagnosis with ISDN-mediated remote microscopy, Virchows Arch. 437 (2000), 52-57.

[42] E.L. Yeo, K.M. Yu, N.C. Poddar, P.K. Hui and L.C. Tang, The accuracy of intraoperative frozen section in the diagnosis of ovarian tumors, J. Obstet. Gynaecol. Res. 24 (1998), 189-195. 


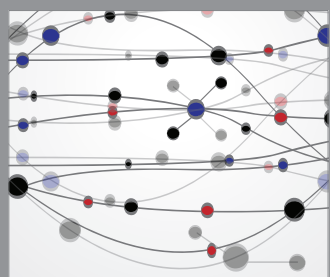

The Scientific World Journal
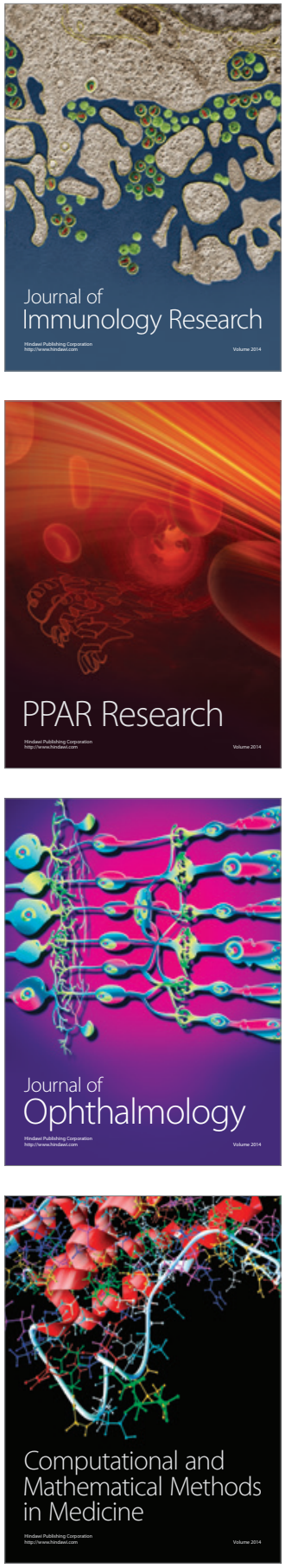

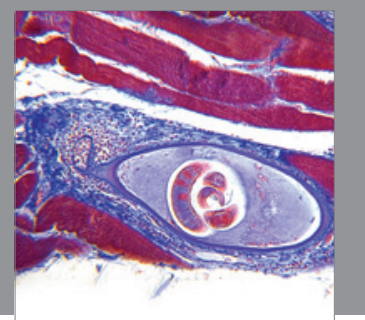

Gastroenterology

Research and Practice
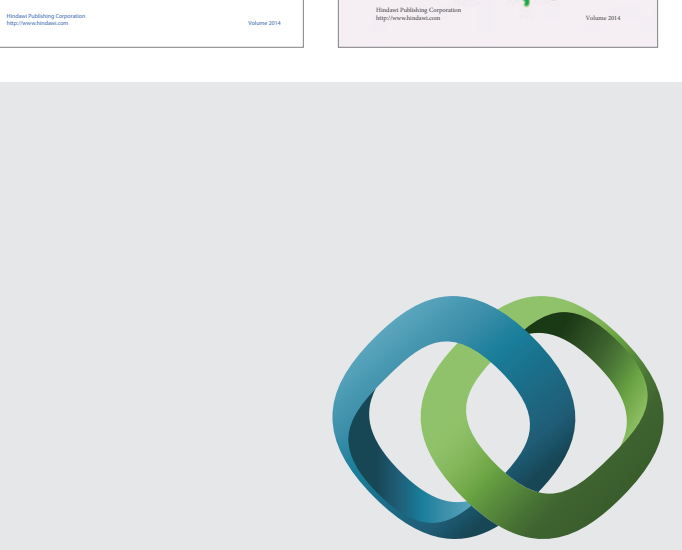

\section{Hindawi}

Submit your manuscripts at

http://www.hindawi.com
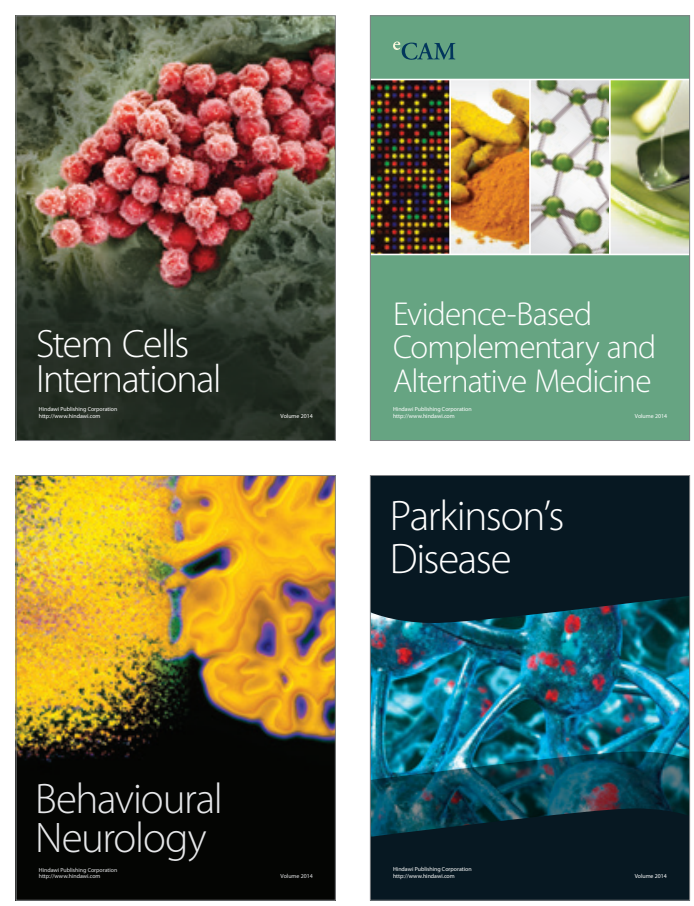

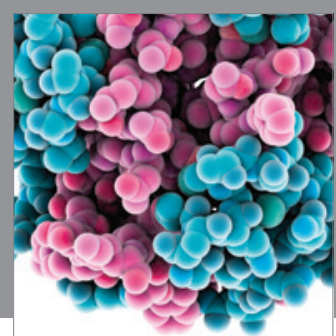

Journal of
Diabetes Research

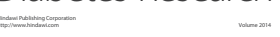

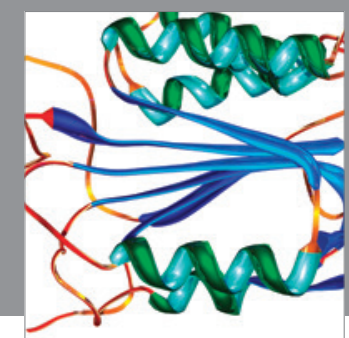

Disease Markers
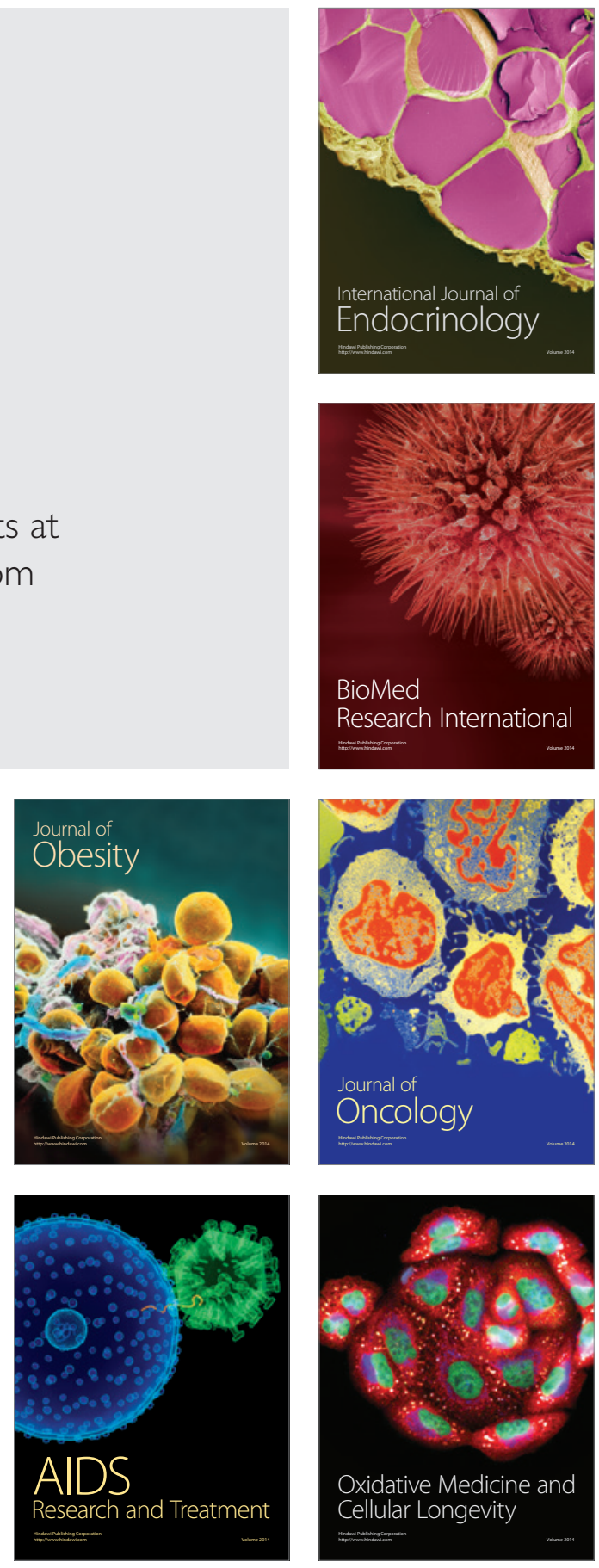